\title{
EL CIUDADANO COMO INFORMADOR Y SUS CONSECUENCIAS EN LA ERA DEL CIBERPERIODISMO
}

\author{
Teresa Egerique Mosquera \\ Universidad de Vigo \\ teresaegerique@uvigo.es
}

Material original autorizado para su primera publicación en la revista académica REDMARKA. Revista Digital de Marketing Aplicado

https://doi.org/10.17979/redma.2009.01.02.4685

\section{Teresa Egerique Mosquera}

Profesora Asociada del Departamento de Derecho Público Especial, Comunicación Audiovisual y Publicidad de la Universidad de Vigo. Doctora en Periodismo por la Universidad de Vigo y Licenciada en Ciencias de la Información por la Universidad San Pablo CEU (Madrid).

La experiencia profesional pasa por nueve años en la Televisión de Galicia como redactora de informativos, programas y corresponsal en Oporto, Portugal. 


\section{RESUMEN}

Este artículo pretende mostrar los peligros con los que se enfrenta el ciudadano por su condición de receptor y de informador. Como receptor por la avalancha de información recibida y la falta de criterio para seleccionar y asimilar las noticias; y como informador por una falta de formación universitaria necesaria para informar correctamente como un profesional. A través del análisis de diferentes espacios en internet que se autodenominan medios de comunicación se llega a la conclusión de que es necesario crear nuevos espacios en los que se diferencie claramente quién es el informador y quien el ciudadano y enseñar a la sociedad a reconocer la información real a través de Internet.

PALABRAS CLAVE:

Internet, periodismo ciudadano, lenguaje periodístico, intrusismo.

\section{ABSTRACT}

CITIZEN AS AN INFORMER AND ITS CONSEQUENCES IN CYBER JOURNALISM ERA

This article aims to show the dangers faced by their citizens for receiving and reporting. As receiver for the avalanche of information and lack of criteria to select and digest the news and as a reporter for lack of academic training required to properly inform a professional. Through the analysis of different sites on the Internet that call themselves media finds it necessary to create new spaces that are clearly distinct and who is the informant who taught the people and society to recognize the information real online.

\section{KEY WORDS:}

Internet, citizen journalist, journalistic languaje, intrusiveness 
"Con Internet, cada ciudadano podrá ejercer de periodista al menos una vez en la vida"

Dan Guillmor

\section{La responsabilidad social del periodista. El nuevo periodista multimedia}

La doctrina de la "responsabilidad social del periodista" fue elaborada en un contexto cultural anglo- americano de posguerra, en un clima de fuerte crítica frente a una comunicación social cuyo comportamiento era considerado servil con las grandes empresas y los anunciantes, resistente al cambio social, superficial y sensacionalista, contrario a la moral pública y carente de respeto por la intimidad de la vida privada. La "teoría" postulaba la responsabilidad de los periódicos y de los periodistas frente a la sociedad y al público, contrariando el radicalismo de las versiones ultraliberales. Las principales funciones atribuidas a los medios de comunicación por la doctrina de la "responsabilidad social" consistían en proveer a los ciudadanos de la información necesaria para el debate político, defender los derechos individuales, contribuir al desarrollo de la economía a través de la prestación de servicios, divertir y, finalmente asegurar su propia autonomía, con el fin de resistir a las presiones externas. La "responsabilidad social" reivindica la necesidad de un periodismo explicativo, con el fin de contextualizar los hechos, así como la transformación de los periódicos en espacios de debate y de crítica, abiertos a la pluralidad de opiniones.

La declaración de la Unesco sobre los medios, que data de 1983, condensa (en el principio tercero) lo esencial de la teoría al afirmar : "En el periodismo, la información es entendida como un bien social y no como un simple producto. Eso significa que el periodista comparte la responsabilidad de la información transmitida, siendo por tanto, responsable no sólo frente a quienes controlan los 
medios, sino, en último análisis, frente al gran público, tomando en cuenta la diversidad de intereses sociales. La responsabilidad social del periodista le exige actuar en todas las circunstancias en conformidad con su propia conciencia ética" . El desarrollo de ese principio establece que la información es entendida como un bien social y no como un producto, algo que hoy en día ha cambiado. Ha cambiado porque los medios a través de los cuales se difunde la información también han cambiado y cualquier ciudadano, ese gran público al que se dirige la información puede convertirse en informador. Más adelante veremos los riesgos que esa acción conlleva.

Los estudiantes que acuden a la Universidad para convertirse en informadores profesionales adquieren una serie de conocimientos académicos relacionados con la disciplina de la comunicación que no poseen el resto de los ciudadanos. Sin embargo las nuevas tecnologías y la unión cada vez más intensa entre televisión y espectáculo, hacen creer lo contrario y ponen al alcance de cualquiera la posibilidad de ser partícipe en la tarea de informar. En ese sentido considero que habría que diferenciar claramente, sobre todo en Internet, las múltiples formas de información y definir el concepto de periodismo digital?, ciberperiodismo?, información en la red?...etc.

Antes de hablar del mal llamado periodismo ciudadano, hay que establecer el concepto de un nuevo periodista, adaptado a las nuevas tecnologías, que aparece con el desarrollo de Internet. A la radio, los periódicos y la televisión se une Internet como medio de comunicación, que, paradójicamente agrupa a los tres anteriores con la ventaja de poder consumirse, casi, en cualquier parte del mundo. Si tomamos Internet como nuevo soporte para comunicar, surge un nuevo tipo de profesional, pero su tarea está al alcance de cualquiera, ya que todo ciudadano que acceda a Internet tiene la capacidad de informar.

Entonces, ¿cómo definimos al periodista digital? La mayoría de los medios de comunicación (radio, televisión y prensa) poseen una página web y difunden 
información a través de Internet. En ocasiones es una mera reproducción de lo emitido radiofónica y audiovisualmente, pero en la mayor parte de los casos las versiones digitales se esfuerzan por actualizar cada pocos minutos la información con titulares sugerentes e imágenes y vídeos de apoyo. Pero actualmente este proceso, tarea propia de la actividad periodística, lo desarrollan numerosos ciudadanos que presencian sucesos o conocen informaciones o rumores de interés público. En Internet los medios de comunicación no compiten sólo entre ellos, sino que lo hacen también con blogs y otro tipo de páginas web en las que todos podemos opinar e informar al mismo nivel que un periodista profesional.

La importancia de Internet en los grupos de comunicación es tan elevada que algunos han comenzado a desarrollar redacciones de informativos multimedia, es decir, integrada por periodistas que desarrollen la información para radio, televisión, periódico e Internet. Así, The Tribune Company, grupo que se encarga de editar el diario The Chicago Tribune, tres diarios regionales, y además posee dos cadenas estatales de televisión, cuatro estaciones de radio y una división editorial, propugnan este nuevo perfil laboral de periodista, implantándolo en su redacción con el fin de llegar a una convergencia de medios; un periodista que trabaje por igual para periódicos, radio, televisión e Internet.

El periodista multimedia, por tanto, es el profesional que puede trabajar en cualquier medio o formato, dominando todas las técnicas e instrumentos para recabar, procesar y emitir información en cualquiera de ellos. Por lo tanto Internet ha cambiado el modelo de comunicación tradicional, las empresas de comunicación y el perfil del periodista. El periodista necesita adquirir unos conocimientos tecnológicos de los que antes podía prescindir. Muchos son los conceptos empleados para designar a estos nuevos profesionales. Davis A. Patten habla de "tecnoperiodistas" o "teleperiodistas". Ignacio Ramonet propone el cambio del término de "periodista" por el de "instantaneista" (analista del instante), o "inmedialista" (analista de lo inmediato). Fernández Hermana lo denomina "cartógrafo", dada la dificultad de manejarse en un entorno digital todavía en 
construcción. Alfonso Cornellá emplea el concepto de "infonomista" (profesional que estudia las estructuras comunicacionales y diseña economías y flujos óptimos de información). Ahora bien, también se habla de "ciberperiodista", "periodista en red" o "periodista multimedia". Estas figuras en ocasiones son periodistas tradicionales adaptados a Internet, pero ya proliferan los periodistas que triunfan en la red sin pasar por la redacción de un periódico, radio o televisión, como es el caso de Matt Drudge que en su web fue la primera persona en destapar el escándalo de la becaria estadounidense Mónica Lewinsky. Casos como ese, con menor relevancia se están convirtiendo en rutina de muchos informativos, que descubren noticias a través del portal "YouTube". Me refiero, por ejemplo a carreras de coches ilegales, peleas en centros de menores o robos grabados in situ por testigos directos.

Es absolutamente necesario, por tanto, adaptar la formación académica de los periodistas (comunicadores), en cualquiera de sus vertientes, a la era digital, aunque la interactividad entre el emisor y el recpetor y el acceso abierto a cualquier ciudadano complica esa actividad. Hay muchos casos en los que el periodista no tiene que pasar por la redacción del medio para el que trabaja para redactar y montar sus artículos y noticias correspondientes a un tema que acaben de cubrir. Simplemente escribirán desde el mismo lugar del suceso, tecleando sobre ordenadores portátiles, equipados con una serie de programas de diseño, procesador de textos y gráficos, con lo que ganarán en rapidez y efectividad, ya que a través de su ordenador podrán asistir a reuniones vía videoconferencia y recibir vía módem el diseño de los espacios asignados a sus artículos, reportajes, comentarios o informes, con las indicaciones necesarias para que encaje en el periódico o el informativo.

Hago un apunte aquí sobre la reducción de costes que ha supuesto Internet en lo que a corresponsalías se refiere. El corresponsal de un canal de televisión ya no precisa aquella infraestructura técnica para la elaboración de noticias analógicas, ni las vías de conexión. La era digital permite realizar el video en un ordenador y 
enviar la noticia por Internet.

Estoy segura de que en un futuro, no demasiado lejano, todo periodista acabará siendo "digital", de igual forma que todo receptor podrá opinar públicamente sobre la información que recibe, cuándo, dónde y cómo quiera.

\section{El nuevo periodismo ciudadano.}

En el siglo XXI el escenario comunicativo ofrece una nueva imagen. Internet ha marcado un mapa informativo renovado. Pero el sistema mediático no sólo ha cambiado para los que trabajamos en él, sino para los ciudadanos, ya que tienen acceso a nuevas vías para la intervención en los procesos comunicativos. Los desafíos del pasado prevalecen pero Internet no se detiene, por eso la situación se ha agravado y urgen respuestas. El panorama de comunicación en Europa, marcado por brechas digitales entre los distintos países y dentro de cada país, tiene como principal objetivo la construcción de un amplio mercado interno y de una economía competitiva en el mundo. Desde el punto de vista de las libertades públicas, el crecimiento cultural y el funcionamiento de los medios de comunicación, quedan muchos desafíos por resolver. Uno de ellos es la regulación y autorregulación debido a los desajustes en el funcionamiento de los medios o en el cumplimiento de sus objetivos en las sociedades plurales y democráticas actuales. Las leyes deben fijar los criterios generales para poder actuar en cada escenario concreto. El Derecho establece un mínimo común denominador que todos los medios y sus profesionales deben respetar y cumplir. Pero es insuficiente. Hay que fijar criterios y principios éticos, establecer un conjunto de mecanismos que contribuyan a una comunicación más responsable en esta compleja sociedad actual.

Sin embargo es una tarea en la que deben implicarse gobernantes y empresas de comunicación, así como las Universidades, una vez establecidos los parámetros de actuación de cara a la sociedad. Uno de los principales problemas es que los 
propios profesionales pecan y permiten el intrusismo descarado en su profesión. El ciberperiodismo tiene como consecuencia inmediata el mal llamado "periodismo ciudadano", término mal empleado, ya que si el periodismo es una disciplina profesional, no puede ser ciudadano, así sería inútil hablar de "medicina ciudadana" o "derecho ciudadano", pero existe del mismo modo que el periodismo ciudadano ya que Internet y sus blogs permiten al ciudadano informar y opinar de cualquier materia, con los peligros que eso conlleva al ser aquellos comentarios accesibles a personas de todas las clases sociales, de todos los niveles culturales y de todas las edades. Lo que se entiende por "periodismo ciudadano" debería denominarse "foro ciudadano", "apuntes de la ciudadanía", "aportaciones ciudadanas"; un término en el que no apareciesen los conceptos de comunicación, información o periodismo. Deberíamos educar a la ciudadanía (sin ánimo de hacer apología de la polémica asignatura en el sistema educativo español) al amparo de esos términos, como exclusivos del periodismo y de los periodistas profesionales.

Tal y como está planteado, por tanto actualmente el periodismo a través de la red, entraña una serie de peligros y riesgos para la evolución de la profesión periodística, pudiendo convertirse en un paso atrás y no adelante. Sin embargo Internet es un arma de doble filo, como casi todas las armas, y bien empleada la Red nos ofrece infinidad de ventajas a los periodistas, hasta el punto de que en pocas décadas todo el consumo de información se hará a través de Internet.

Internet ofrece la posibilidad de ser reconocido como periodista por tus trabajos individualmente, sin necesidad de una empresa de comunicación para la que trabajes. En ese sentido, un periodista con los medios suficientes (que hoy en día son accesibles), puede cubrir noticias y redactar desde su condición de profesional de la información, a través de Internet para todo el mundo, en su página web propia. Si realiza bien su profesión serán noticias con una estructura determinada, investigadas, contrastadas, bien redactadas e imparciales. Pero además ese periodista puede escribir columnas de opinión y participar en debates y tertulias sin moverse de casa. Este es un uso periodístico correcto de Internet, además de 
la colaboración y trabajo exclusivo para las diferentes páginas digitales de los medios de comunicación escritos y audiovisuales.

Un uso incorrecto del periodismo en Internet, o en el mejor de los casos, tan sólo un término empleado incorrectamente es el de los sitios web en los que los ciudadanos informan desde su condición de meros ciudadanos, pero como si de periodistas se tratara. Es el caso de la página web www.periodismociudadano.com. La última publicación que me llama la atención es de un tal Craig Newmark, el fundador de "craighlist", un sitio web de anuncios clasificados con una red centralizada de comunidades urbanas y foros clasificados. Ese hombre, sin ser una persona interesada en la política ha visto la necesidad en las últimas elecciones norteamericanas de tomar partido por uno de los candidatos debido, dice, a la corrupción que existe actualmente en Estados Unidos. La participación activa de los ciudadanos, insiste, puede ayudar a eliminar esa corrupción. Se ha grabado en video dando un discurso y lo ha publicado en Internet en "www.citizenjournalism.com", que sigunifica periodismo ciudadano.

Cualquiera tiene un espacio para aportar datos, comunicarse y hacerse escuchar. No diré, de momento que tiene espacio para comunicar o informar, por lo delicado de los términos cuando hablamos de periodismo. Y como hemos comprobado en el caso de Craug Newmark, lo hacen con una intención u objetivo, no sólo por el mero hecho de informar.

Existe otro tipo de mal llamado periodismo ciudadano, con proyección, sobre todo en los informativos televisivos. En España, en estos últimos años las empresas de comunicación y, en ocasiones los servicios públicos han tirado piedras sobre su propio tejado, ya que ha proliferado (y todavía se practica) la difusión de imágenes de videoaficcionado, e incluso han abierto informativos de carácter nacional. Me ha llamado la atención en estos últimos días un anuncio en la Televisión de Galicia (televisión autonómica de esa comunidad) en el que facilitan una dirección de correo electrónico y un teléfono para mostrar vídeos, testimonios y fotos de 
sucesos, sin más condición que la de poseer una cámara y un ordenador. Me resulta completamente ofensivo que en una televisión donde trabajan cientos de profesionales de la comunicación primen testimonios e imagenes grabadas por un ciudadano, del que no se sabe qué fuentes ha utilizado ni qué intención persigue con la difusión de la noticia, seguramente será la de ganar dinero. Además solicitarlo públicamente a través de un espacio insertado en bloques publicitarios me parece que degrada y agrade al profesional periodista.

Otra cosa es emplear imágenes de videaficcionado, por ejemplo, como complemento de una información elaborada, contrastada e investigada por un periodista determinado (me refiero a imágenes de temporales, desastres naturales), que siempre pueden nutrir la noticia y ampliar visualmente la infomación que se le ofrece al receptor. Sí es verdad que pueden llegar a ser documentos valiosos, pero tratados antes por un periodista en la redacción. Por eso hay que saber diferenciar bien las funciones de cada uno y enseñar a las sociedad a diferenciarlas. Son los propios medios de comunicación los que fomentan la participación ciudadana, pero deben aprender a hacerlo desde un punto de vista educativo y mostrando una serie de pautas y condiciones que no siempre se ponen de manifiesto. En ocasiones imágenes grabadas por ciudadanos, de muy mala calidad, han abierto informativos nacionales. Por eso con acciones como esas cualquier ciudadano puede sentirse informador, periodista, sin saber que una información engañosa, no contrastada y falsas puede hacer mucho daño a la sociedad.

El caso más reciente, que más me ha llamado la atención en España ha sido el del accidente de Barajas, en agosto de 2008. Un avión de Spanair sufrió un accidente cuado despegaba del aeropuerto madrileño rumbo a las Islas Canarias. Durante las diez horas posteriores al accidente los medios de comunicación (televisiones y ediciones digitales de los periódicos) emitieron más imágenes grabadas por los ciudadanos residentes en los alrededores del aeropuerto (videoaficcionados), que de los propios profesionales que necesitaron algún 
tiempo para desplazarse al lugar de los hechos.

Este tipo de periodismo existía ya encarnado en la figura del "freelance" o "freelander", un trabajador autónomo, cuentapropia e independiente, pero al fin y al cabo periodista. Un freelance realiza su profesión de forma autónoma, para terceros y obtiene su retribución por tiempo empleado, o por noticia obtenida. $A$ partir de mediados de los noventa el freelander encuentra un filón en la información de sociedad, y es entonces cuando se multiplican los intrusos y se triplican las agencias, cámaras y fotógrafos, que venden las informaciones como productos muy cotizados y a un elevado precio. Una de las mayores sombras de la profesión periodísticas la encontramos en los denominados programas del corazón, ya que los testimonios de los ciudadanos y de los periodistas profesionales se sitúan al mismo nivel confundiendo claramente al público.

\section{La perversión en los contenidos y la pobreza del lenguaje.}

Estamos asistiendo, cada vez con más frecuencia, a una pérdida de rigor absoluta en las informaciones, un rigor que es absorvido por la espectacularidad, la inmediatez y el suceso. Las fuentes han perdido su importancia y su papel. Hoy en día, y de cara al futuro, si no le ponemos freno, la fuente será la masa y la masa será la que informe. El periodista será un protagonista del foro, o en el mejor de los casos un empresario que gestione el blog, página o periódico digital especializado en un tema del que participen todos los ciudadanos del mundo. Desde mi punto de vista los más jóvenes no entienden el periodismo como lo entendían sus padres, y es que el periodismo se está convirtiendo en espectáculo, tensión, morbo y suceso, suceso y puro suceso. Proliferan las noticias de asesinatos, de juicios y detenciones, así como operaciones policiales y peleas entre vecinos. Este tipo de noticias generan el uso de términos y expresiones de un lenguaje especializado relacionado con la delincuencia y con el derecho, que se está popularizando y en muchas ocasiones aparece mal empleado por el 
desconocimiento absoluto de esos términos y de su significado. Ese tipo de noticias, que a día de hoy ocupa el $80 \%$ de un informativo, son las que provocan en los bloggers e internautas deseos de convertirse en protagonistas de la noticia o autores de la misma. Ese deseo, al alcance de su mano, se hace realidad, ya sea la noticia verdadera o falsa, por eso muchos blogs se convierten en mentideros digitales, por eso se alerta contra el peligro de la rapidez, la información espectáculo y la falta de rigor. El profesor Carlos González Reigosa asegura que "la realidad se convierte en una tupida malla que nos impide ver (...) la realidad sobre la que se debería informar. (...) hay que encontrar maneras de lograr la confianza y la exactitud en el nuevo periodismo" Para ello es importante alfabetizar a las personas en un mundo nuevo donde el escepticismo debe ser tenido en cuenta.

La mayoría de las noticias que se emiten a diario en los informativos podrían cubrirse por cualquier ciudadano con una cámara, un micrófono y algo de destreza. Me estoy refiriendo a que los acontecimientos y lugares a los que antes sólo se accedía con acreditación como profesional para dar cobertura informativa al evento, son ya los menos. Los directores de informativos descartan congresos, cumbres o actividades elitistas, y rellenan las escaletas con múltiples sucesos, noticias de índole social o rencillas personales entre familiares o vecinos. ¿Lo hacen por lo cercano del caso, por tratarse de problemas cotidianos?, ¿es verdad que cada vez toma un papel más relevante en la sociedad la información local? Yo creo que sí, por una sencilla razón, porque el ciudadano se convierte en protagonista de la noticia y conoce a casi todas las personas que conforman la información de su ciudad, pueblo o barrio.

Considero el párrafo anterior de suma importancia y el origen de la proliferación de los blogs y del mal llamado, insisto, "periodismo ciudadano". Con su participación en YouTube, o en cualquier blog, el ciudadano se siente útil, escuchado y, en ocasiones protagonista de la noticia, con una diferencia sustancial a la de los medios de comunicación locales. En Internet lo que hace, dice y graba puede ser 
visto y escuchado por cualquiera en cualquier parte del mundo, algo, que de momento, no sucede con la noticia de su televisión local. Este hecho le hace sentirse todavía más importante, y casi siempre obtendrá alguna respuesta de alguien que, como él cree que debe ser escuchado. Así la red comienza a tejerse y el peligro acecha al periodista profesional y al periodismo como disciplina de comunicación, ya que las "supuestas" informaciones se convierten en conversaciones por la pobreza del lenguaje y su dudoso contenido.

Es innegable que para escribir sobre cualquier tema no hay que ser periodista, pero para escribir en un medio de comunicación sí. Entonces, se pregunta el profesor Koldo Meso, si se considera a la red como un entorno de comunicación, ¿por qué no redactan los periodistas los contenidos que la forman?

A día de hoy nos resulta imposible controlarlo. El público pasivo de los medios tradicionales se ha convertido en usuario activo y eso es imparable ya que el número de usuarios de Internet va en aumento. El público ya no se contenta únicamente con el consumo de medios cada vez más interactivos, sino que también participa en la producción de los contenidos que más le interesan. Estoy de acuerdo con el Profesor Koldo Meso cuando dice que el periodista actual debe saber a qué tipo de usuario se dirige, quién es, qué quiere y qué necesita.

Para responder a esas preguntas con su actividad profesional empleará la narrativa hipertextual, que es la nueva forma de comunicar los hechos. Permite que el receptor pueda ir más allá de las informaciones escogidas por el periodista ya que le ofrece los enlaces a las páginas de sus fuentes, a elementos de contextualización, a datos complementarios, a las páginas de los protagonistas, e incluso le ofrece la posibilidad de que los lectores puedan aportar datos, convirtiéndose en emisor a partir de sus propias averiguaciones. Tiene muchas ventajas como modelo crítico de análisis de la información, siempre y cuando se sepan las intenciones de los usuarios. 
Lo que no podemos pasar por alto es el lenguaje que emplea el receptor en casos como el que acabamos de describir. El dinamismo y la inmediatez son dos características que definen la información a través de Internet y eso, en ocasiones, dificulta la correcta redacción de los mensajes. Un profesional, que trabaja en un medio de comunicación adquiere, por práctica y experiencia la capacidad de ser, inconscientemente, un puente entre la información y el lector. Encuentra esa información, la mastica, la contrasta y crea un artículo comprensible para un elevado número de personas. Cuando un ciudadano se pone en la piel del periodista, y quiere convertirse también en un puente entre la información y el lector, el resultado no es el mismo, al puente le faltan pilares. Ese individuo no tiene la formación del periodista y por lo tanto a la hora de redactar lo más probable es que se deje llevar por el dramatismo, la hipermotividad, la banalización y la espectacularidad, entre otras muchas sensaciones, por lo que su artículo estará impregnado de parcialidad. Además la composición de su noticia corre muchos riesgos. Con la palabra tendencia a emplear eufemismos, empobrecimiento del lenguaje y confusión entre información y opinión; el tratamiento de las imágenes puede ser también incorrecto y podría cometer eufemismos visuales, ofrecer el lado más vulgar de las imágenes o pecar por exceso y mostrar más de lo que debe; finalmente el partícipe, mal llamado informador, con toda seguridad exponga informaciones interesadas o fabricadas por él mismo, en respuesta a esa necesidad de participar en el foro.

Para acabar con este apartado, aportar un dato que espero compartan conmigo, y es que para leer algún artículo de calidad, o informaciones relevantes y de contundencia intelectual muy pocos, por no decir ninguno elige el ordenador. Siempre es mejor imprimir la información y leerla en papel. Es por eso que en Internet se utiliza un lenguaje más directo, menos literario y más concreto que en los diarios y revistas. Se impone, por tanto, el lenguaje audiovisual. Y añado dos citas de Loic Le Meur:

"Si bien los periodistas deben seguir la linea editorial del medio para el que 
trabajan y tienen un espacio limitado, los bloggers escriben cuando quieren, lo que quieren y del modo que quieren. No tienen límites ni de extensión ni de audiencia" "La interactividad de los bloggers y sus lectores es, sin duda, donde radica la importancia actual de los blogs"

\section{El futuro incierto}

- Uno de los cambios de cara al futuro, relacionado con Internet puede ser el fin de la gratuidad en el uso de la red. Las previsiones indican que habrá que pagar en muchos accesos que actualmente son gratuitos. Lo mismo pasa con la televisión, aunque a mi juicio habría que establecer una tarifa conjunta para consumir Internet y televisión a la carta, con unos contenidos de calidad superior a la de otros espacios financiados por la publicidad.

- Los contenidos cobran importancia por su calidad. Entre los consumidores de Internet habrá receptores que exijan calidad en las informaciones, y la tendrán siempre y cuando la información la realicen periodistas profesionales en medios que no descuiden la selección de esos contenidos por llevar a cabo estrategias empresariales relacionadas con la captación de audiencia, o que le den preferencia a la cantidad y no a la calidad. Se puede hacer y ofrecer periodismo de calidad a través de Internet.

- Los periódicos digitales se rinden ante los medios audiovisuales y prácticamente todas las noticias incluidas en las publicaciones incluirán un video de apoyo, algo que ya existe hoy en día.

- Hay que crear espacios virtuales para potenciar la información, verdadera, el periodismo en su esencia. Espacios en los que sólo puedan producir informaciones periodistas profesionales y en los que haya reportajes, entrevistas, donde se pueda contratar información y encontrar artículos de opinión de 
profesionales relevantes y de cierta categoría. Con este tipo de espacios la profesión periodística podría salvarse ante una realidad en la que cada vez está más desacreditada.

- Cuanta más información tenga el internauta, mayor serán sus posibilidades de elegir, así que en el futuro habrá que olvidarse de monopolios y ofrecer la mayor cantidad de información posible y conseguir fidelizar al público según sus preferencias.

- Muchos periodistas podrán crear su propio medio de comunicación en Internet, así que se convertirán en empresarios. Ha de aprender a gestionar su empresa, porque las rutinas periodísticas ya las conoce. Es importante que los periodistas adquieran conocimientos de marketing y publicidad para explotar correctamente su medio.

- Igualmente en el caso de los gabinetes de prensa. Dejan de tener un espacio físico para convertirse en periodistas con un espacio virtual en donde el periodista que redacta la información encuentra casi toda o toda la información que necesita de las empresas a las que pertenece el gabinete.

- El tiempo y el lenguaje cobran especial importancia en los medios de comunicación digitales. La elección de titulares que inciten a abrir esa noticia es fundamental, y que se cargue rápido tan o más importante todavía. Una larga espera hará al consumidor cambiar de espacio y elegir otro medio. La mayor parte de los diarios, radios y televisiones poseen su página en Internet, pero muchos no han sabido adaptarse al medio digital. Su espacio en Internet no pude ser un calco del medio en sí, debe cumplir una serie de requisitos atractivos para el internauta, que decide acceder a esos medios a través de la red. Internet posibilita la síntesis de los tres medios en uno, y a mi entender es la tendencia del futuro, ya que el ordenador o el teléfono serán nuestra televisión, nuestra radio y nuestros periódicos. Se crea así un nuevo medio de comunicación que se podría llamar 
"multimediador".

\section{Referencias bibliográficas.}

\section{$\underline{\text { Libros }}$}

Aznar, H., (2005), Comunicación responsable. La autorregulación de los medios, Editorial Ariel, Barcelona, 2005.

Boczkowski, P. J., (2006) Digitalizar la noticias. Innovación en los diarios online, Editorial Manantial, Buenos Aires, 2006

Díaz Noci, Javier, Larrañaga Zubizarreta, José, Larreta Arondo, Ainara, Meso Ayerd, Koldo, (2007) El impacto de Internet en los medios de comunicación vascos, Servicio Editorial de la Universidad del País Vasco, Bilbao, 2007.

López García, G., (2005), Modelos de comunicación en Internet, Editorial Tirant lo Blanch, Valencia, 2005.

López García, Xosé, Otero López, M., (2007), Bitácoras, la consolidación de la voz del ciudadano, Netbiblo, A Coruña, 2007.

Meso Ayerdi, Koldo (1993), Introducción al ciberperiodismo. Breve acercamiento al estudio del periodismo en Internet. Servicio Editorial de la Universidad del País Vasco, Bilbao, 1993.

Mesquita, Mario (2007), El cuarto equívoco. El poder de los media en la sociedad contemporánea, Editorial Fragua, Madrid, 2007.

Vilches, L., (2001), La migración digital, Editorial Gedisa, Barcelona, 2001.

\section{$\underline{\text { Publicaciones }}$}

Meso Ayerdi, Koldo, (junio de 2002), "La penúltima revolución", Revista Baquia, HYPERLINK http://www.baquia.com/articulos_autor.php?autor=113.

Meso Ayerdo, Koldo, (junio de 2002), "El pulso de los usuarios", Revista Baquia, HYPERLINK http://www.baquia.com/noticias.php?id=8997.

Parejo, Melanie, (enero 2001), "Querido diario online", el-mundo.es. HYPERLINK http://www.el-mundo.es/2001/01/29/internet/e000136.html.

Peirano, Marta (2002), "La nueva prensa", el-mundo.es, ariadna., HYPERLINK 
http://www.el-mundo.es/ariadna/2002/87/1017907984.html.

\section{Para citar este artículo:}

Egerique Mosquera, Teresa EL CIUDADANO COMO INFORMADOR Y SUS CONSECUENCIAS EN LA ERA DEL CIBERPERIODISMO.

REDMARKA - CIECID - Unidad de Investigación en Marketing Aplicado-Universidad de A Coruña, Número 2, V1, pp.55-72

ISSN 1852-2300

URL del Documento : http://www.cienciared.com.ar/ra/doc.php?n=1095 